\title{
Symbiotic bacteria (Erwinia sp.) in the gut of Frankliniella occidentalis (Thysanoptera: Thripidae) do not affect its ability to transmit tospovirus
}

\author{
Egbert J. DE VRIES ${ }^{1}$, Fennet VAN DE WETERING ${ }^{2}$, Marieke M. VAN DER HOEK², Gerrit JACOBS ${ }^{1}$ \\ and JOHANNES A.J. BREEUWER ${ }^{1}$
}

\author{
${ }^{1}$ Institute for Biodiversity and Ecosystem Dynamics, University of Amsterdam, PO Box 94248, Science Park 904, 1090 GE, \\ Amsterdam, The Netherlands; e-mail: vries@science.uva.nl \\ ${ }^{2}$ Laboratory of Virology, Department of Plant Science, Wageningen University, Droevendaalsesteeg 1, 6708 PB, Wageningen, \\ The Netherlands
}

\begin{abstract}
Key words. Erwinia, TSWV, virus-bacteria interaction, larval stage, Frankliniella occidentalis, Thripidae
\end{abstract}
\begin{abstract}
Tomato spotted wilt virus (TSWV) is one of the most harmful plant viruses and one of its most important vectors is the western flower thrips [Frankliniella occidentalis Pergande (Thysanoptera: Thripidae)]. Recently, we reported the close association of Erwinia sp. gut bacteria with this species of thrips. The first instar larvae acquire these bacteria from their food source. A high proportion of adult western flower thrips transmit TSWV after acquiring the virus during the first larval stage when there are no bacteria in their gut. A considerably lower proportion of adults that acquire the virus early in the second instar transmit virus and none of those exposed to virus late on in the second instar do so. The highest prevalence and total number of symbiotic bacteria are recorded in the guts of second instar thrips. This leads to the hypothesis that the build up of bacteria in the gut reduces the acquisition of TSWV, resulting in a lower capacity to transmit the virus. To test this hypothesis, the transmission of this virus by symbiotic and aposymbiotic adult thrips of the NL3 population was studied. Comparison of virus transmission by adult thrips, the larvae of which either had or lacked gut bacteria and were exposed to virus in either the first or second instar, revealed no difference in the ability of symbiotic and aposymbiotic adults to transmit this virus. We conclude that virus transmission is not affected by the number of the symbiotic bacteria Erwinia sp. present in the gut of thrips larvae.
\end{abstract}

\section{INTRODUCTION}

Western flower thrips, Frankliniella occidentalis Pergande (Thysanoptera: Thripidae), is a small phytophagous insect, which has spread world-wide over the last 30 years from its original habitat in the western part of the United States. Thrips are major world-wide insect pests (Lewis, 1997). Apart from the direct damage they cause to plants, this species is also the most important vector of Tomato spotted wilt virus (TSWV). This virus has a large host range and ranks among the most devastating plant viruses (Goldbach \& Peters, 1994).

Thrips transmit TSWV in a propagative manner (Ullman et al., 1993; Wijkamp, 1995). There are six steps in the transmission process: ingestion of virus into the midgut, replication in the midgut epithelium and midgut muscle cells, transfer of the virus to the salivary glands, replication in the salivary glands, release of the virus into the saliva and finally injection of saliva containing the virus into plants (Whitfield et al., 2005). This implies a latency period between the moment of acquisition of the virus and the first transmission of virus. The larvae ingest the virus from infected plant leaves along with their food, which passes into their midgut. The virus enters epithelial cells in the first region of the midgut (Ullman et al., 1993; Nagata et al., 1999; Whitfield et al., 2005), where it replicates and subsequently infects the midgut muscle cells. Later, virus particles are found in the salivary glands. The mechanism by which the virus can pass from the midgut to the salivary glands is still not fully understood.

In their review article, Whitfield et al. (2005) indicate three possible routes by which tospoviruses may reach the salivary glands. In the first, the virus migrates from the midgut lumen to the salivary glands after replicating in the migut and different organs in the hemocoel. There is no evidence to support this hypothesis. In the second, the virus is transported via cellular structures (tubular salivary glands and ligaments) connecting the midgut with the salivary glands (Ullman et al., 1993; Nagata et al., 1999). In the third, the virus is transferred to the glands during the early development of the thrips, when the salivary glands are in contact for a short period with the midgut (Moritz et al. 2004). Immuno-labelling of viral proteins has revealed that replication of the virus occurs in the midgut and salivary glands (Ullman et al., 1993; Wijkamp et al., 1993). Nagata et al. (1999) revealed the presence of nucleocapsid proteins in the ligament structures connecting the midgut with the salivary glands using immuno-labelling techniques and that the first site of infection in salivary glands is the point where these ligaments are attached to the glands.

Thrips have two larval stages. The first instar has a developmental time of approximately 2.3 days (Van Rijn et al., 1995), when reared at approximately $25^{\circ} \mathrm{C}$, whereas the second larval stage requires almost 3.7 days at this temperature. Van de Wetering et al. (1996) show that 
adults are efficient transmitters when they are fed as first instar larvae on TSWV infected plant material. This efficiency drops rapidly with age and is almost zero when the virus is acquired in the last hours of the first larval stage. Only a few of the young second instar individuals that ingest virus become transmitters (Van de Wetering et al., 1999). This was shown for one population of thrips and may not be the case for other populations (Van de Wetering et al., 1999).

In addition to infection with virus, thrips also harbour bacteria. Ullman et al. (1989) record finding numerous bacteria in the midgut and, in particular, the hindgut of all thrips. We have shown that a species of Erwinia is always present in the guts of thrips (De Vries et al., 2001a). This was demonstrated by growing bacteria from a homogenate of individual thrips on a rich growth medium. The bacteria were identified as a species of Erwinia. Direct isolation, amplification and sequencing of bacterial $16 \mathrm{~S}$ rDNA in homogenates of thrips also indicate that Erwinia bacteria are present, so we concluded that this bacterium is the dominant species in the gut of thrips. Based on a16S rDNA sequence analysis the bacteria present in the gut of various thrips populations from different host plants are similar. All older larvae harbour high numbers of bacteria. The youngest larvae are free of bacteria, because they are not transmitted to the next generation vertically but horizontally (De Vries et al., 2001b). The gut bacteria have to be acquired via food contaminated by the bacteria in frass, saliva, and faeces of other thrips (De Vries et al., 2008). Gut bacteria have been found in various populations of Frankliniella occidentalis world wide. Chanbusakarum \& Ullman (2008, 2009) record similar strains of Erwinia sp. in different populations of this thrips living in California and De Vries (2010) in all $F$. occidentalis populations infesting crops in greenhouses in various countries in North and South America, Europe and Asia.

Variation in the capacity of the various stages to ingest or transmit viruses has been previously recorded (Ammar, 1994; Van de Wetering, 1999). Several reasons have been suggested to account for this variation, such as, the mid-gut barriers to infection differ between larval stages (Ullman et al., 1992), the barriers between the midgut and salivary glands may differ (Moritz et al., 2004), and/or there is variation in efficiency with which the salivary glands are infected (Nagata, 1999). The omnipresence of gut bacteria in old first and second instar larvae, and their absence in young first instar larvae, led us to formulate the hypothesis that the increase in the number of gut bacteria is negatively associated with the ability to transmit tospovirus, because the bacteria adversely affect the ability of the virus to infect mid-gut epithelial cells and its subsequent transmission. Possible mechanisms are physical hindrance during penetration of gut epithelial cells, or changes in the midgut barrier induced by bacteria at an early stage in the development of the host when virus is migrating through the periderm or the microvilli, or a direct adverse effect of bacteria on the virus. Negative interactions between gut bacteria and other gut organisms are recorded for the grasshopper Schistocerca gregaria, in which the gut bacterium Enterobacter agglomerans eliminates the entomopathogenic fungi used to control this insect pest (Dillon et al., 2000). In whiteflies (Bemisia tabaci), one species of secondary symbiont, of the Hamiltonella type, produces a specific GroEL protein, which enhances transmission of a plant virus (Tomato yellow leaf curl virus) (Gottlieb et al., 2010). In order to test the above hypothesis postulated for thrips, we compared the success of normal (symbiotic) thrips and bacteria-free (aposymbiotic) larvae and adults of thrips in transmitting virus.

\section{MATERIAL AND METHODS}

\section{Thrips}

The thrips used in this study were taken from the NL3 population maintained in the Laboratory of Virology of Wageningen University for over 8 years (Van de Wetering et al., 1999). This population was originally collected from infested bean plants in a greenhouse in the Netherlands. This population was reared on bean pods (Phaseolus vulgaris) at $25^{\circ} \mathrm{C}, 60 \%$ relative humidity and a $16 \mathrm{~L}: 8 \mathrm{D}$ photoperiod (standard conditions for rearing thrips). Bean pods were obtained from local grocery stores, thoroughly washed with water to remove any thrips, kept in an incubator for 5 days, then washed again to remove any newly hatched larvae, before use at room temperature.

\section{TSWV isolate and plant material}

We used the Brazilian TSWV isolate BR-01, described and classified by De Ávila et al. (1990), in the experiments. This virus isolate was maintained on Datura stramonium plants by inoculation by thrips. The plants used to infect the thrips with virus in this experiment were mechanically inoculated with TSWV not naturally by thrips, in order to assure that the only thrips on the plants were the thrips to be tested. Systemically infected Datura leaves used for acquisition of virus by thrips had a similar virus load to those infected by thrips (data not shown). Petunia $\times$ hybrida "Polo Blue" leaf disks were used to test virus transmission efficiency as described by Wijkamp et al. (1993) and Van de Wetering et al. (1996). Petunia and Datura plants were grown in thrips-free greenhouses $\left(22^{\circ} \mathrm{C}\right.$ and $60 \%$ $\mathrm{RH})$.

\section{Detection of gut bacteria}

Gut bacteria in thrips were isolated by homogenising individual thrips in $100 \mathrm{ml}$ homogenisation buffer (phosphatebuffered saline (PBS) containing $0.14 \mathrm{M} \mathrm{NaCl}, 1 \mathrm{mM} \mathrm{KH}_{2} \mathrm{PO}_{4}$, $8 \mathrm{mM} \mathrm{Na}_{2} \mathrm{HPO}_{4}, 2.5 \mathrm{mM} \mathrm{KCl}$ and Tween 20 at pH 7.4). We did not use the TE buffer that was used by de Vries et al. (2001a), but this change in buffer does not affect the viability of the reference bacterial strain TAC.XII.93.8 (data not shown) and therefore unlikely to affect that of gut bacteria. The bacteria were similar to Erwinia sp., consisting of small motile rods producing small round white-opaque colonies on Luria-Bertoni (LB) medium. This growth medium is considered to be one of the best for supporting the growth of Erwinia sp. gut bacteria (De Vries et al., 2001a). To check the identity, 20 randomly chosen colonies from a few different homogenates of thrips were grown in pure cultures and their biochemical characteristics determined using the API 20E identification kit (Biomérieux Benelux BV). They all had an API 20E pattern similar to the reference strains (De Vries et al., 2001a).

Three replicate experiments were done to test whether the adults are able to transmit their gut bacteria to the next genera- 
TABle 1. Design of the experiment used to determine the efficiency with which aposymbiotic (Apo) and symbiotic (Sym) western flower thrips transmit Tomato spotted wilt virus. The proportions of adults that transmitted virus, after acquiring virus in the first (L1) or second larval (L2) stage, were recorded.

\begin{tabular}{ccc}
\hline \multirow{2}{*}{ Virus acquisition } & \multicolumn{2}{c}{ Presence of bacteria } \\
\cline { 2 - 3 } & Symbiotic & Aposymbiotic \\
\hline Uptake in first & Sym L1 & Apo L1 \\
larval stage & (A) & (B) \\
Uptake in second & Sym L2 & Apo L2 \\
larval stage & (C) & (D) \\
\hline
\end{tabular}

tion when infesting the host plants used in this study. Approximately 50 female adult thrips were placed on Petunia hybrida leaf discs and on Datura stramonium plants and allowed to lay eggs for one day. In each replicate, 25 second instar thrips were collected from the host plant and tested for the presence of gut bacteria. A thrips was considered positive when more than 30 colonies of the TAC type were observed on a plate from each homogenate tested. Samples that resulted in fewer than 30 colonies were considered as negative.

\section{Production of similar aged aposymbiotic and symbiotic thrips}

To determine the effects of gut bacteria on virus transmission, aposymbiotic and symbiotic thrips of similar age were required. The symbiotic thrips used were larvae of approximately the same age. They were produced by placing approximately 100 adult female thrips on bean pods for $24 \mathrm{~h}$. Two methods were used to produce the aposymbiotic thrips. In the first a $1 \mathrm{mg} / \mathrm{ml}$ tetracycline solution was offered to 100 females placed in a Murai cage for $24 \mathrm{~h}$ (Murai \& Ishii, 1982). The females imbibe the antibiotic when they feed on the solution, which is placed between two Parafilm layers prior to the start of the experiment. Earlier studies show that this treatment is effective in eliminating gut bacteria (De Vries et al., 2001b). The females were subsequently transferred to clean bean pods, and the larvae were collected when they were $0-24 \mathrm{~h}$ old. In the second, eggs that were collected as they were laid, which are free of Erwinia, were used (De Vries et al., 2004). These can be obtained if female thrips are allowed to feed and oviposit in Murai cages, because in these cages the eggs are laid in sterile water enclosed between two layers of parafilm. These eggs were individually transferred to fresh, clean bean leaf discs where they hatched and developed into larvae.

\section{Efficiency with which the virus is transmitted}

There were two experiments on virus transmission; one used antibiotic treated thrips and the other aposymbiontic thrips that hatched from uninfected isolated eggs. Each group was split into two subgroups (Table 1). One subgroup was allowed to acquire virus on the first day after hatching (L1 acquisition groups) by feeding for $24 \mathrm{~h}$ on infected Datura leaf discs from mechanically inoculated plants. The other subgroup was kept on virusfree plants during the first larval stage (L2 acquisition groups). This subgroup was subsequently, in the L2 phase, confined for $24 \mathrm{~h}$ on leaves from virus infected plants. During the preacquisition and acquisition period the thrips were maintained on leaves in Tashiro cages (Tashiro, 1967). The transmission of virus by these subgroups was compared with that of subgroups consisting of symbiotic thrips, which also acquired the virus during either the first or second instar (Table 1).

After virus acquisition, thrips were transferred to virus-free Petunia leaf discs and allowed to develop into adults. Thrips
TABLE 2. Presence of gut bacteria in second instar larvae of the western flower thrips from population NL3 reared on Petunia or Datura plants. $\mathrm{n}$ - number of thrips tested, \% pos. percentage of thrips with Erwinia sp. gut bacteria.

\begin{tabular}{lcccccc}
\hline \multirow{2}{*}{ Date } & \multicolumn{2}{c}{ Petunia } & & \multicolumn{2}{c}{ Datura } \\
\cline { 2 - 3 } \cline { 5 - 6 } & $\mathrm{n}$ & \% pos. & & $\mathrm{n}$ & \% pos. \\
\hline November 1996 & 22 & 55 & & 24 & 83 \\
December 1996 & 26 & 77 & & 14 & 71 \\
January 1997 & 18 & 66 & & 25 & 100 \\
\hline
\end{tabular}

were transferred to fresh leaf discs twice a week. In the next step, adult thrips were tested for their ability to transmit virus to Petunia leaf discs, which produce local lesions when infected with the virus, as previously described by Wijkamp \& Peters (1993) and Van de Wetering et al. (1996). Virus transmission was recorded positive when two or more of the Petunia leaf discs fed on by an individual thrips developed local lesions. All experiments were carried out under standard thrips growth conditions in a climate box. After the experiment, we tested for the presence of bacteria in each thrips by homogenising the thrips and growing the bacteria in each homogenate on rich growth medium.

Differences between the thrips groups were statistically evaluated using $\chi^{2}$-tests. We tested the presence of bacteria and virus transmission efficiency in aposymbiotic and symbiotic thrips against a 50\%:50\% null hypothesis, and the presence of bacteria and virus transmission efficiency in L1 and L2 acquisition subgroups against a 50\%: $50 \%$ null hypothesis. Only thrips for which both factors (gut bacteria and virus transmission efficiency) were successfully determined were included in the $\chi^{2}$ tests.

\section{RESULTS}

\section{Erwinia bacteria in the NL3 thrips population}

Thrips from population NL3 used in this study, like those from other populations, were always infested with Erwinia gut bacteria (Table 2 and De Vries et al., 2001a). These gut bacteria were found in most of the larvae that fed on the host plants used in this study. Gut bacteria were transmitted to the next generation of thrips when they fed on Datura and Petunia (data not shown), as previously reported for thrips feeding on bean and cucumber (De Vries et al., 2001b). The number of second instar larvae that became infected on these plants was not always $100 \%$ as in previous experiments (De Vries et al., 2001b). This difference in the incidence of infection may be due to difference in the time it takes the larvae to develop on Datura and Petunia plants compared to bean and cucumber plants used in previous studies. We confirmed that the bacteria found in the NL3 thrips were indeed Erwinia sp. by checking a few samples using the API 20E test (data not shown).

\section{Efficiency with which the virus is transmitted}

The first experiment on the efficiency with which TSWV is transmitted was done using four different subgroups of thrips (Table 1). The subgroups differed in when the acquired the virus (during the first or second larval stage) and whether there were bacteria in their guts (symbiotic or aposymbiotic). Thrips were made aposym- 
TABle 3. Presence of Erwinia sp. gut bacteria in symbiotic and aposymbiotic L2 larvae as described in Table 1. Symbiotic thrips were untreated and should contain Erwinia sp. gut bacteria (Sym). Aposymbiotic thrips were fed the antibiotic tetracycline (Apo) in their drinking water, which should have killed the gut bacteria. L1 - virus ingestion in first larval stage, L2 ingestion in second larval stage. Bacterial infection is given as the percentage of thrips infected with gut bacteria in the adult phase (\% inf.)

\begin{tabular}{lcccc}
\hline \multirow{2}{*}{ Thrips group } & \multicolumn{3}{c}{ Bacteria } \\
\cline { 3 - 5 } & & infected & uninfected & \% inf. \\
\hline Sym L1 & $\mathrm{A}$ & 41 & 40 & 51 \\
Apo L1 & $\mathrm{B}$ & 3 & 36 & 8 \\
Sym L2 & $\mathrm{C}$ & 31 & 14 & 69 \\
Apo L2 & $\mathrm{D}$ & 4 & 16 & 20 \\
\hline
\end{tabular}

biotic by feeding them on a solution of tetracycline. This antibiotic treatment was highly effective. The proportion of bacteria-infested thrips was lower ( $8 \%$ of L1 and $20 \%$ of L2 acquisition groups) in the antibiotic treated subgroups than the symbiont subgroups (52\% of L1 and $69 \%$ of L2 acquisition groups) (Table 3). This was significant at $\mathrm{p}<0.001$ level (Table 5). Both groups were exposed to a virus source. The proportion of symbiotic adults, which acquired the virus as first instar larvae, that transmitted the virus was 0.69 , and as second instar larvae, was 0.04 (Table 4). Similarly the proportion of adults of the L1 aposymbiotic group that transmitted virus was much greater than that of the L2 aposymbiotic group. The proportions transmitting virus was 0.73 for acquisition in the first larval stage and 0.04 in the second (Table 4). There was no significant difference between aposymbiotic and symbiotic adult thrips in the proportions that transmitted virus after acquiring virus in either the first or second larval stage $(\mathrm{p}>0.1$, Table 5$)$.

In the second experiment, aposymbiotic thrips were obtained by isolating eggs. The results of this experiment were similar to the previous experiment. In both acquisition groups of aposymbiotic thrips, the percentages with a bacterial infection $(6 \& 7 \%)$ were considerably less than in those of symbiotic thrips (86 \& 100\%) (Table 6).

TABLE 4. Proportions of western flower thrips that transmitted Tomato spotted wilt virus (TSWV). The various thrips groups are described in Table 1. Symbiotic thrips had Erwinia sp. gut bacteria (Sym). The mothers of aposymbiotic thrips were fed the antibiotic tetracycline in their drinking water (Apo). L1 - virus ingested in first larval stage, L2 - virus ingested in second larval stage. Virus transmission (using a local lesion test) was determined for individual thrips. transmission - proportion of thrips that successfully transmitted virus.

\begin{tabular}{llccc}
\hline \multirow{2}{*}{ Thrips group } & \multicolumn{3}{c}{ Virus transmission } \\
\cline { 2 - 5 } & & no & yes & Transmission \\
\hline Sym L1 & A & 24 & 54 & 0.69 \\
Apo L1 & B & 11 & 30 & 0.73 \\
Sym L2 & C & 81 & 3 & 0.04 \\
Apo L2 & D & 47 & 2 & 0.04 \\
\hline
\end{tabular}

TABLE 5. Statistical analysis of the effect of the presence of gut bacteria on the transmission of Tomato spotted wilt virus (TSWV) by adult western flower thrips, based on data from Tables 3 and 4 . The data were analyzed using $\chi^{2}$ tests. Codes $\mathrm{A}, \mathrm{B}, \mathrm{C}$ and D refer to Table 1 . $\mathrm{df}$ - degrees of freedom.

\begin{tabular}{|c|c|c|c|c|c|c|}
\hline \multirow[t]{2}{*}{ Treatment } & \multicolumn{3}{|c|}{$\begin{array}{c}\text { Aposymbiotic } \\
\text { vs. symbiotic } \\
\text { (B + D vs. A + C) }\end{array}$} & \multicolumn{3}{|c|}{$\begin{array}{l}\text { First instar larvae } \\
\text { vs. second instar } \\
(\mathrm{A}+\mathrm{B} \text { vs. } \mathrm{C}+\mathrm{D})\end{array}$} \\
\hline & $\chi^{2}$ & $\mathrm{df}$ & $\mathrm{p}$-value & $\chi^{2}$ & $\mathrm{df}$ & $\mathrm{p}$-value \\
\hline Bacteria & 32.4 & 3 & $<0.001$ & 6.23 & 3 & 0.1 \\
\hline $\begin{array}{l}\text { Larval } \\
\text { stage }\end{array}$ & 0.37 & 3 & 0.95 & 71.6 & 3 & $<0.001$ \\
\hline
\end{tabular}

Acquisition of virus in the first larval stage resulted in a higher percentage of the adults transmitting than when acquiring it in the second larval stage. In the symbiotic groups, transmission efficiency was $33 \%$ and $4 \%$ and in the aposymbiotic groups $36 \%$ and $9 \%$, respectively, as expected (Van de Wetering et al., 1996). Apparently, virus uptake and transmission efficiency was not affected by the presence of bacteria (Table 7).

\section{DISCUSSION}

The results of both the experiments on virus transmission show that first instar larvae of thrips of population NL3 are able to acquire TSWV and that a high proportion of them can transmit the virus to test plants when they are adults. Intake of virus only in the second instar rarely leads to successful transmission in the adult phase [confirming the results of Van de Wetering et al. (1996); and others (see Whitfield et al., 2005)].

The proportions of adults transmitting virus was lower in the second than in the first experiment (see Tables 4 and 7). This may be due to a slight difference in the virus load of the inoculated leaves, slight differences in the temperatures during the acquisition and/or the time the larvae take to develop from larva to adult, and the age of the infected leaves fed to the larvae. The differences in efficiency between the experiments lead, however, to the same general observation that the proportion transmitting virus is not affected by the presence of gut bacteria,

TABLE 6. The percentages of the different groups of western flower thrips infected with Erwinia sp. gut bacteria. The different subgroups are described in Table 1. Symbiotic thrips are untreated thrips that should contain gut bacteria (Sym). Bacteria-free thrips were made aposymbiotic by rearing larvae that hatched form isolated eggs (Apo). Thrips were allowed to ingest virus in the first (L1) or second larval stage (L2). Presence of bacteria was tested using a homogenate of individual adult thrips ( $\%$ inf - percentage of thrips infected with bacteria).

\begin{tabular}{llccc}
\hline \multirow{2}{*}{ Thrips group } & \multicolumn{3}{c}{ Bacteria } \\
\cline { 2 - 5 } & & infected & uninfected & $\%$ inf \\
\hline Sym L1 & A & 25 & 4 & 86 \\
Apo L1 & B & 2 & 29 & 6 \\
Sym L2 & C & 30 & 0 & 100 \\
Apo L2 & D & 2 & 27 & 7 \\
\hline
\end{tabular}


TABLE 7. Percentage of adult western flower thrips that transmitted Tomato spotted wilt virus. The different subgroups are described in Table 1. Symbiotic thrips are those with gut bacteria (Sym). Bacteria-free thrips were made aposymbiotic by rearing larvae that hatched from isolated eggs (Apo). Thrips were allowed to ingest virus in the first (L1) or second larval stage (L2). The percentage of adults that transmitted the virus was determined by recording the incidence of local lesions that developed on a Petunia leaf disk fed on by an adult for two days. Transmission - percentage of thrips that successfully transmitted virus.

\begin{tabular}{llccc}
\hline \multirow{2}{*}{ Thrips group } & \multicolumn{3}{c}{ Virus transmission } \\
\cline { 3 - 5 } & & no & yes & Transmission (\%) \\
\hline Sym L1 & A & 31 & 15 & 33 \\
Apo L1 & B & 25 & 14 & 36 \\
Sym L2 & C & 47 & 2 & 4 \\
Apo L2 & D & 39 & 4 & 9 \\
\hline
\end{tabular}

because similar proportions of adults of both symbiotic and aposymbiotic thrips transmitted virus in each experiment. In all of the experiments we found that some of the thrips presumed to be aposymbiotic did contain a large number of gut bacteria. This may be due to the fact that the antibiotic treatment was not $100 \%$ successful for all thrips, or due to the accidental picking up of the right type of bacteria from a fresh leaf disc. It is not possible to carry out these experiments in a strictly sterile environment.

We hypothesised that the build-up of gut bacteria during larval development has a negative effect on viral intake and would lower the efficiency with which the adult thrips transmit virus. Contrary to this hypothesis, the bacteria did not negatively (nor positively) affect virus transmission. Transmission of virus is considerably lower when virus is acquired by second instar than first instar larvae, whether gut bacteria are present in the thrips or not. Antibiotic treated aposymbiotic and symbiont groups of thrips show a similar level of TSWV transmission, both when the virus is acquired in first and second larval stage (Tables 4 and 7). Thus, the antibiotic tetracyclin, used to produce thrips free of symbiotic gut bacteria, does not have a negative effect on virus transmission. The treatments used to produce aposymbiotic thrips in this study resulted in very low numbers of infected thrips. However, given the detection methods we used, it cannot be excluded that there is a very small number of bacteria present in the guts of the aposymbiotic thrips. If a very small number of bacteria can affect virus transmission then the results of this study would have to be interpreted differently.

Several reasons can be suggested to explain why bacteria do not affect virus acquisition and transmission. First, a physical separation may exist between the locations where the gut bacteria multiply and where the virus replicates. Upon acquisition, virus replicates in the anterior part of the midgut (region MG1, Nagata et al., 1999), whereas bacteria reside in the hindgut (Ullman et al., 1989; De Vries et al., 2001a). In addition, Kikkert et al. (1998) who looked for a biochemical interaction between gut bacteria and virus report that the major virus binding protein of thrips that is expressed in the midgut does not interact with Erwinia bacteria. Finally, an important part of the virus transmission pathway in thrips is the migration from the midgut epithelium to the salivary glands. It is suggested that this occurs by the binding of the virus to and transport via the ligaments between gut and salivary glands that this is a crucial factor in successful transmission (Nagata, 1999). This part of the virus transmission cycle in thrips is unlikely to be affected by bacteria that live in the gut.

More research is needed on the migration of virus in thrips, in particular, the enzymes, tissues and mechanisms that are involved in order to be able account for why the transmission of virus is much lower when second instar larvae are exposed to infection than first instar larvae. We have shown that the presence of bacteria plays no role, either negative or positive, in the transmission of tospoviruses.

ACKNOWLEDGEMENTS. The authors wish to thank Novartis BV (the Netherlands) for the Petunia seeds. We thank M.W. Sabelis, S.B.J. Menken and D. Peters for comments on earlier version of this manuscript. The first four authors were supported by grant ABI 22.2704 from the technology foundation of the Netherlands Organization of Science. The Royal Netherlands Academy of Arts and Sciences supported J.A.J. Breeuwer.

\section{REFERENCES}

Ammar E.D. 1994: Propagative transmission of plant and animal viruses by insects: Factors affecting vector specificity and competence. Adv. Dis. Vector Res. 10: 289-331.

Chanbusakarum L. \& Ullman D.E. 2008: Characterization of bacterial symbionts in Frankliniella occidentalis (Pergande), Western flower thrips. J. Invertebr. Pathol. 99: 318-325.

Chanbusakarum L. \& Ullman D.E. 2009: Distribution and ecology of Frankliniella occidentalis (Thysanoptera: Thripidae) bacterial symbionts. Environ. Entomol. 38: 1069-1077.

De Ávila A.C., Huguenot C., Resende R. de O., Kitajima E.W., Goldbach R.W. \& Peters D. 1990: Serological differentiation of 20 isolates of tomato spotted wilt virus. J. Gen. Virol. 71: 2801-2807.

DE VRIES E.J. 2010: Symbiosis of Thrips and Gut Bacteria. PhD Thesis, University of Amsterdam, $173 \mathrm{pp}$.

De Vries E.J., Breeuwer J.A.J., Jacobs G. \& Mollema C. 2001a: The association between western flower thrips, Frankliniella occidentalis, and Erwinia species gut bacteria, transient or permanent? J. Invertebr. Pathol. 77: 120-128.

De Vries E.J., Jacobs G. \& Breeuwer J.A.J. 2001b: Growth and transmission of gut bacteria in the western flower thrips, Frankliniella occidentalis. J. Invertebr. Pathol. 77: 129-137.

De Vries E.J., Jacobs G., Breeuwer J.A.J., Sabelis M.W. \& MenKen S.B.J. 2004: Diet dependent fitness effects of gut bacteria on their insect host: the symbiosis of Erwinia sp. and western flower thrips. Proc. R. Soc. Lond. (B) 271: 2171-2178.

De Vries E.J., Van der Wurff A., Jacobs G. \& Breeuwer J.A.J. 2008: Onion thrips (Thrips tabaci) have gut bacteria that are closely related to the symbionts of western flower thrips (Frankliniella occidentalis). J. Insect Sci. 23: 1-11.

Dillon R.J., Vennard C.T. \& Charnley A.K. 2000: Exploitation of gut bacteria in the locust. Nature 403: 851 .

Goldbach R.W. \& Peters D. 1994: Possible causes of the emergence of tospovirus diseases. Seminars Virol. 5: 113-120. 
Gottlieb Y., Zchori-Fein E., Mozes-Daube N., Kontsedalov S., Skaljac M., Brumin M., Sobol I., Czosnek H., Vavre F., Fleury F. \& GHanim M. 2010: The transmission efficiency of Tomato Yellow Leaf Curl Virus by the Whitefly Bemisia tabaci is correlated with the presence of a specific symbiotic bacterium species. J. Virol. 84: 9310-9317.

Kikkert M., Meurs C., Van de Wetering F., Dorfmüller S., Peters D., Kormelink R. \& Goldbach R.W. 1998: Binding of Tomato spotted wilt virus to a $94-\mathrm{kDa}$ thrips protein. Phytopathology 88: 63-69.

LewIS T. 1997: Thrips as Crop Insects. CAB International, New York, NY, 740 pp.

Moritz G., Kumm S. \& Mound L. 2004: Tospovirus transmission depends on thrips ontogeny. Virus Res. 100: 143-149.

MuraI T. \& IshII T. 1982: Simple rearing methods for flower thrips (Thysanoptera: Thripidae) on pollens. Jpn. J. Appl. Entomol. Zool. 26: 149-154 [in Japanese].

Nagata T. 1999: Competence and Specificity of Thrips in the Transmission of Tomato Spotted Wilt Virus. PhD thesis, Wageningen Agricultural University, 96 pp.

Nagata T., Inoue-Nagata A.K., Smid H.M., Goldbach R.W. \& Peters D. 1999: Tissue tropism related to vector competence of Frankliniella occidentalis for tomato spotted wilt tospovirus. J. Gen. Virol. 80: 507-515.

TASHIRO H. 1967: Selfwatering acrylic cages for confining insects and mites and detached leaves. J. Econ. Entomol. 60: 354-356.

Ullman D.E., Westcott D.M., Hunter W.R. \& Mau R.F.L. 1989: Internal anatomy and morphology of Frankliniella occidentalis (Pergande) (Thysanoptera: Thripidae) with special reference to interactions between thrips and tomato spotted wilt virus. Int. J. Insect Morph. Embryol. 18: 89-310.

Ullman D.E., Cho J.J., Mau R.F.L., Westcott D.M. \& Custer D.M. 1992: A midgut barrier to tomato spotted wilt virus acquisition by adult western flower thrips. Phytopathology 82: $1333-1342$.
Ullman D.E., German T.L., Sherwood J.L., Westcott D.M. \& CANTONE F.A. 1993: Tospovirus replication in insect vector cells: Immunocytochemical evidence that the non-structural protein encoded by the S RNA of tomato spotted wilt tospovirus is present in thrips vector cells. Phytopathology 83: 456-463.

VAN DE Wetering F. 1999: Effects of Thirps Feeding on Tospovirus Transmission in Chrysanthemum. PhD thesis, Wageningen University and Research Centre, $120 \mathrm{pp}$.

Van de Wetering F., Goldbach R.W. \& Peters D. 1996: Tomato spotted wilt tospovirus ingestion by first instar larvae of Frankliniella occidentalis is a prerequisite for transmission. Phytopathology 86: 900-905.

Van de Wetering F., Van der Hoek M.M., Goldbach R.W., Mollema C. \& Peters D. 1999: Variation in tospovirus transmission between populations of Frankliniella occidentalis (Thysanoptera: Thripidae). Bull. Entomol. Res. 89: 579-588.

Van Rijn P.C.J., Mollema C. \& Steenhuis-Broers M.M. 1995: Comparative life-history studies of Frankliniella occidentalis and Thrips tabaci (Thysanoptera: Thripidae) on cucumber. Bull. Entomol. Res. 85: 285-297.

Whitfield A.E., Ullman D.E. \& German T.L. 2005: Tospovirus-Thrips interactions. Annu. Rev. Phytopathol. 43: 459-489.

WIJKAMP I. 1995: Virus-Vector Relationships in the Transmission of Tospoviruses. PhD Thesis, Wageningen Agricultural University, $141 \mathrm{pp}$.

WiJKAmP I. \& Peters D. 1993: Determination of the median latent period of two tospoviruses in Frankliniella occidentalis, using a novel leaf disk assay. Phytopathology 83: 986-991.

Wijkamp I., Van Lent J., Kormelink R., Goldbach R.W \& Peters D. 1993: Multiplication of tomato spotted wilt virus in its insect vector, Frankliniella occidentalis. J. Gen. Virol. 74: 341-349.

Received September 26, 2011; revised and accepted January 10, 2012 